\title{
Species richness on islands in time: variation in ephemeral pond crustacean communities in relation to habitat duration and size
}

\author{
Bonnie J. Ripley · Marie A. Simovich
}

Received: 1 August 2007 /Revised: 12 June 2008/Accepted: 1 August 2008/Published online: 7 September 2008

(C) Springer Science+Business Media B.V. 2008

\begin{abstract}
Ephemeral ponds are doubly insular habitats in that they are discrete in time as well as in space. Predicting species richness based on pond size has been attempted using measures of both spatial extent and habitat duration, but habitat qualities alone only drive community composition under the speciessorting metacommunity paradigm. We tested the hypothesis that community composition in temporary ponds is driven by species sorting due to pond duration. In order to eliminate bias due to undersampling, we sampled 34 pools distributed among 3 complexes in every ponding event over a period of six years, and identified every individual for the microcrustacean taxa. Our data were consistent with most of the predictions of the species-sorting hypothesis. There was a clear pattern of difference between ponds in species richness as well as higher species richness in years with higher rainfall. The set of crustacean species that we found in the pools was highly significantly nested across the region, but not necessarily within localized groups of ponds (complexes). We also found differences in community composition among complexes. Pond depth was the best predictor of species richness when data were
\end{abstract}

Handling editor: S. Declerk

B. J. Ripley $(\bowtie) \cdot$ M. A. Simovich

Department of Biology, University of San Diego,

5998 Alcalá Park, San Diego, CA 92110, USA

e-mail: bonnie.ripley@gcced.edu summarized over the whole study, but in one year with unusually high rainfall, pond area and hydroperiod were significant but depth was not. We did find some species in all ponds. It is likely that given their short development time, ponds do not differ in habitat quality for these few species. These results taken together emphasize the variability inherent in ephemeral pond ecology, with detectable differences in crustacean communities and the factors influencing them between years as well as between ponds, and at scales of meters as well as kilometers. Although our data provide further evidence that species sorting on pond permanence is an important factor structuring temporary pond crustacean communities, our assumption that dispersal is not limiting still needs to be tested.

Keywords Metacommunity · Habitat permanence . Island biogeography · Temporal variation .

Southern California vernal pool

\section{Introduction}

For aquatic invertebrates, freshwater ponds are oases of suitable habitat within a matrix of unsuitable habitat, reminiscent of island archipelagoes (Dodson, 1992; Fryer, 1985). Ephemeral freshwater ponds are especially interesting, as their bi-phasic nature makes them "islands" in time as well as in space (Ebert \& Balko, 1987). Although insular biogeographic theory 
(McArthur \& Wilson, 1967) may seem like a useful paradigm for prediction of species richness in ephemeral ponds, defining habitat size is problematic in part because pond size changes during the inundation cycle. Measures like maximum pond area can be good predictors of community richness (Brooks \& Hayashi, 2002; Helm, 1998; King et al., 1996; March \& Bass, 1995) but increasing habitat permanence, measured as ponding duration or hydroperiod, has also been shown to successfully predict higher species richness (Bohonak \& Jenkins, 2003; Ebert \& Balko, 1987; Eitam et al., 2004; Jeffries, 2001; Schneider \& Frost, 1996; Wissinger et al., 1999). These studies report on different taxonomic groups from ponds with hydroperiods ranging from days to months, and in diverse ecological settings, so it is not clear if the different results are due to pond type differences or that island biogeographic theory alone is incapable of predicting species richness in temporary ponds.

An alternative paradigm for understanding temporary pond community composition is the metacommunity (Wilson, 1992). The metacommunity concept extends the metapopulation concept to include multiple species in each habitat patch. It attempts to incorporate regional dispersal-mediated processes, interspecific interactions within habitat patches, and inter-patch differences in habitat quality (Mouquet \& Loreau, 2002, 2003). Leibold et al. (2004) recognized ephemeral aquatic habitats as systems that fit the metacommunity definition especially well. Leibold et al. (2004) also outlined four paradigms regarding metacommunity structure and dynamics, namely patch dynamics, species sorting, mass effects, and a neutral model. These paradigms are distinguished by whether patches differ and whether dispersal between patches is more important than interspecific interactions within patches. The patch dynamics model assumes that patches are the same, so dispersal between patches is the only driving factor. The species-sorting mechanism assumes that patches differ and that species are found in different patches due to adaptations to these differences. The mass effects model pertains to systems where movement of individuals between patches is common, and the neutral model assumes all species are functionally the same. The taxa present in temporary ponds have been shown to be a non-random subset of the locally available species (Stevens \& Jenkins, 2000), so the species-sorting (pond characteristics) and mass effect (dispersal) models are the most attractive in this habitat.

An increasing number of freshwater pond ecologists have been profitably framing research questions in terms of the metacommunity concept (e.g. Leibold $\&$ Norberg, 2004). Some of these studies have shown that dispersal moderates local factors in freshwater ponds (Cottenie et al., 2003; Havel \& Shurin, 2004; Kneitel \& Miller, 2003). However, most studies on ephemeral ponds support the hypothesis that communities are mainly determined by species sorting, and that the important difference between ponds is permanence (Rundle et al., 2002; Urban, 2004; Jocqué et al., 2007; Brooks, 2000). Pools of short duration will exclude long-lived species that cannot reproduce before the pool dries, predators have insufficient time to invade, and competitive exclusion does not go to completion (Schneider \& Frost, 1996).

Determining the relative importance of local and regional processes in temporary ponds must take into account qualitative differences in dispersal among pond species. Some species are eliminated from the pond when it dries and must re-colonize with each pond filling, while others persist during the dry phase in a dormant state, ready to emerge as soon as the pond fills (Wiggins et al., 1980). Insects are a major component of the first group. Dispersal is critical to their success, and while they tend to accumulate in ponds as time passes after filling, they may be absent from the community due to chance events (McAbendronth et al., 2005; Rundle et al., 2002). In contrast, crustaceans have special adaptations to survive the dry phase in situ, generally by the production of desiccation resistant eggs or encysted embryos that can remain dormant long periods of time (Wiggins et al., 1980; Williams, 1985). Crustaceans may have conditional entry or exit from diapause, or have a true diversified bet-hedging strategy (Brendonck, 1996; Philippi et al., 2001; Ripley et al., 2004; Simovich \& Hathaway, 1997). All of these function as a hedge against extirpation, since pond duration varies relative to maturation time. True extinctions (whether short-term or permanent) are thus rare for these species, as rescue and re-colonization can take place from within the system (Bohonak \& Jenkins, 2003).

Because of this life history strategy, spatial dispersal for crustaceans is passive and must generally occur via transport of the propagules by wind, 
water flow, or animal vectors (Bohonak \& Jenkins, 2003). However, there is no general consensus as to the extent or importance of dispersal for these organisms, which may even vary across species and habitat types (Bohonak \& Jenkins, 2003). Differences in species composition among even closely spaced pools and among filling events within a pool may be attributable to random chance, or differences in life history or physiology (García et al., 1997; Graham, 2002; Hall et al., 2004; King et al., 1996; Mahoney et al., 1990; Schneider \& Frost, 1996). Thus, the presence or absence of a particular temporary pond crustacean over time is likely to be due to factors other than spatial colonization and extinction.

Although there is a general consensus in the temporary pond literature that life history adaptations to pond duration are the major factor determining which species are found in particular ponds (Schneider \& Frost, 1996; Urban, 2004; Vanschoenwinkel et al., 2007), there are two reasons this conclusion may be misleading. The first is that extensive sampling programs are required to characterize temporary pond faunas. Species composition is known to change from one sampling time to another for individual pools (Graham, 2002; Mahoney et al., 1990), as time passes since the pool filled (Hall et al., 2004), and in different years (García et al., 1997). Species that are not abundant, that are present in only a few pools, or that emerge only under rare circumstances may not be detected; therefore the timing of sampling affects which species are detected. As most studies have chosen to sample many ponds once or a few times, or one pond or a few ponds many times (a notable exception: Wissinger et al., 1999), they have drawn their conclusions from incomplete data. The second reason is that observation of any patterns depends on the spatial and temporal scales over which the observations are made, relative to the developmental times and dispersal distances of each species (Jenkins, 2006; Mouquet \& Loreau, 2002; Urban, 2004). The same sampling limitations mentioned above may also limit the ability to detect patterns in metacommunities. We think that using intermediate-scale sampling programs, including many ponds many times, will be needed to untangle community patterns at the intersection of local and regional processes, as Kneitel and Miller (2003) have done in their elegant experiments.

Here, we test the hypothesis that species sorting is due to pond duration using a relatively large data set across a group of ponds that are abiotically similar in most respects except for pond size and duration. We sampled ephemeral pool crustaceans in 37 pools distributed across three distinct pool complexes, which allows us to examine patterns in species occurrence over two spatial scales-within and between complexes. Furthermore, our sampling program extended over six years, and we sampled ponds periodically from filling to drying during every wet phase. This allows us to examine changes in pool faunas in individual ponds as time passes after filling, in different filling events during the same winter, and in the same ponds from year to year.

The first requirement for species sorting to be determined by ponding duration is that ponds differ in duration, and that longer-lived ponds have more species. We first confirmed that ponds differed in species richness, and tested whether these differences were consistent from year to year. We measured ponding duration, pond depth, and pond area because all of these variables have been shown to predict species richness, and because they are correlated, we tested their ability to explain species richness using path analysis. We also used clustering analysis to test if species assemblages, not just numbers of species, showed associations with pond permanence. The second requirement for species sorting to be determined by pond permanence is that the ponds with longer durations have all the species that appear in short duration ponds as well as additional species only found in pools with long durations. We tested for this pattern by testing for nestedness by pond duration. Finally, we examined individual species' phenologies for evidence that the species causing any observed nested patterns were constrained by life history adaptation. Taken together, these analyses allow us to determine if our data are consistent with the species-sorting hypothesis, although without explicitly including spatial variables in our analysis, we cannot conclude that spatial patterns are not important as well.

Our system is suitable for addressing these issues because (1) there are enough crustacean species $(>15)$ to observe differences between ponds in the number of species within a single taxonomic group with similar dispersal and colonization abilities, (2) the hydroperiod (weeks) falls in the middle of the range of hydroperiods for ephemeral ponds in general, which is the range for which life history 
considerations are most important (Schneider \& Frost, 1996), and (3) there is little utilization by waterfowl and sediments are covered with an algal crust during dry periods (Holland \& Jain, 1981), so the two major dispersal vectors for crustaceans that have been observed in other systems (Figuerola \& Green, 2002; Vanschoenwinkel et al., 2007) are not present in ours. In fact gene flow between even closely spaced ponds seems to be very limited (Bohonak, personal communication).

\section{Methods and materials}

Study area

Southern California vernal pools are a subset of ephemeral wetlands that are especially variable in ponding duration. They occur on coastal mesas where southern California's Mediterranean climate is accompanied by microgeographic depressions underlain by an impermeable layer of clay hardpan (Holland \& Jain, 1981). The depressions are irregularly shaped and fill to depths of $5-30 \mathrm{~cm}$ with diameters generally on the order of 1-15 m, depending on rainfall. They occur in clusters (complexes) with pool basins meters to tens of meters apart, and with complexes kilometers apart. Ponding occurs when winter precipitation saturates underlying soils and fills these depressions. Depending on the amount and pattern of rainfall, pools may be filled from days to weeks before drying from evaporation, and may dry and refill multiple times in one winter (Ebert \& Balko, 1987; Philippi et al., 2001). Where it is still natural, the surrounding vegetation is sparse to dense chaparral, and undisturbed ponds have little to no litter or sediment.

Many of the largest complexes of relatively undisturbed, extant vernal pools in Southern California (USA) are found on Marine Corps Air Station Miramar (MCASM, formerly known as Naval Air Station Miramar) and Marine Corps Base Camp Pendleton (Bauder \& McMillan, 1998). MCASM covers over 23,000 acres on the coastal mesas of the central San Diego area (Ebert \& Balko, 1987; Fig. 1), and the vernal pools on the base have been used for a variety of ecological and restoration studies, notably Bauder (1987) who established the naming conventions we use here. We used pools in three complexes designated A4, AA9, and AA10, which were part of a larger study evaluating success of restoration activities. Data on severely degraded pools are not included in these results; moderately disturbed pools are included, as they did not differ in crustacean community indices from control pools, nor did they differ before and after restoration measures were taken on them (Simovich, unpubl. data). Complexes AA9 and AA10 were contiguous before a highway was built through the mesa in the mid-1980s and are about $1 \mathrm{~km}$ from A4. All the pools used for this study are within a few $\mathrm{km}$ of each other and have the same soil type, basins formed by the same geologic and biotic processes, and have extremely localized watersheds (Holland \& Jain, 1981).

Crustacean sampling and environmental measurements

Pools were checked at all complexes after each rainfall event from fall 1997 to spring 2003. We began sampling once a pool held water for at least 10 days because this was the minimum time known for the largest crustacean, the San Diego fairy shrimp, Branchinecta sandiegonensis, to reach sexual maturity when it can be identified to species morphologically (Hathaway \& Simovich, 1996). Pools were re-sampled every 10-14 days thereafter until pools dried. The sampling regime was repeated every time subsequent rainfall later refilled pools in the same winter. Ten to twenty pools per complex filled consistently enough to sample. None of the pools filled long enough to sample in 01-02 so we have five years of data from our six-year study. Only 10 of the pools filled long enough to sample in all of the five years of the study. We did not consider depressions that did not hold water for at least 10 days in at least one year or never had any crustacean species as "pools" and these were eliminated from analysis.

The number of samples taken from a pool (Table 1) represents habitat duration, not sampling effort, because every pool was sampled every time it held water. Pools were not visited often enough to measure hydroperiod-the number of days the pool filled-so we used the number of samples taken from the pond as a measure of pond permanence. On each pond visit, we measured maximum depth with plastic rulers and paced off approximate pool length and width. Total precipitation for each sampling season was calculated as the sum of monthly precipitation 
Table 1 Sampling pattern

\begin{tabular}{|c|c|c|c|c|c|c|c|c|c|c|c|c|c|c|}
\hline \multirow[t]{2}{*}{ Complex } & \multirow[t]{2}{*}{ Pool } & \multicolumn{2}{|c|}{ 97-98 } & \multicolumn{3}{|c|}{ 98-99 } & \multicolumn{2}{|c|}{$99-00$} & \multicolumn{2}{|c|}{ 00-01 } & \multicolumn{3}{|c|}{$02-03$} & \multirow[t]{2}{*}{ Total } \\
\hline & & 1 & 2 & 1 & 2 & 3 & 1 & 2 & 1 & 2 & 1 & 2 & 3 & \\
\hline \multirow[t]{11}{*}{ AA9 } & MC1 & 3 & 3 & & & & & & 1 & & 1 & & & 8 \\
\hline & MC2 & 3 & 2 & & & & & & 2 & & 1 & & & 8 \\
\hline & MC3 & 8 & & & & & 1 & 1 & 2 & & 3 & & & 15 \\
\hline & MC4 & 7 & & 2 & 2 & & 1 & 1 & 3 & & 3 & & & 19 \\
\hline & MK5 & 3 & 2 & 2 & & & & & 2 & & 0 & & & 9 \\
\hline & $139 \mathrm{~W}$ & 9 & & 2 & & & 1 & & 4 & & 4 & & & 20 \\
\hline & $138 \mathrm{E}$ & 9 & & & & & 1 & & 3 & & 2 & & & 15 \\
\hline & K1 & 7 & & 2 & 2 & & 3 & & 7 & & 4 & 1 & & 26 \\
\hline & $\mathrm{K} 2$ & 7 & & 2 & & & 2 & & 3 & & 3 & & & 17 \\
\hline & K3 & 6 & 1 & & & & 2 & & 3 & & 2 & & & 14 \\
\hline & K4 & 7 & & 2 & 1 & & 2 & & 6 & & 4 & & & 22 \\
\hline \multirow[t]{12}{*}{ AA10 } & MC5 & 9 & & 1 & 2 & 2 & 3 & & 7 & & 1 & 4 & 1 & 30 \\
\hline & MC6 & 9 & & 2 & & & 6 & & 1 & 8 & 7 & & & 33 \\
\hline & MC7 & 3 & 2 & & & & & & 1 & & 1 & & & 7 \\
\hline & MC8 & 7 & & & & & & & 2 & & 2 & & & 11 \\
\hline & MR68.1 & 3 & & & & & & & 1 & & 1 & & & 5 \\
\hline & MR68.4 & 2 & & & & & & & 1 & & 1 & & & 4 \\
\hline & MR70.1 & 7 & & 2 & & & 2 & & 3 & & 1 & & & 15 \\
\hline & MR70.2 & 3 & 2 & & & & & & 1 & & 0 & & & 6 \\
\hline & MR74E & 3 & 2 & 1 & & & 1 & & 2 & & 1 & & & 10 \\
\hline & $68.3 \mathrm{E}$ & 8 & & & & & & & 5 & & 4 & & & 17 \\
\hline & $68.3 \mathrm{~W}$ & 7 & & 1 & & & & & 2 & & 2 & & & 12 \\
\hline & 71 & 1 & 2 & & & & 2 & & 2 & & 1 & & & 8 \\
\hline \multirow[t]{9}{*}{ A4 } & MC9 & 6 & & & & & 1 & & 1 & & 1 & & & 9 \\
\hline & MC10 & 3 & 2 & & & & & & 1 & & 1 & & & 7 \\
\hline & MC11 & 3 & 2 & & & & & & 1 & & 1 & & & 7 \\
\hline & MC11B & 3 & 2 & & & & 1 & & 1 & & 2 & & & 9 \\
\hline & MC12 & & & & & & & & 1 & & & & & 1 \\
\hline & MR103.5 & 3 & 2 & & & & 2 & & 5 & & 3 & 1 & & 16 \\
\hline & MR104 & 3 & 2 & & & & & & 1 & & 1 & & & 7 \\
\hline & MR105 & 4 & 2 & 1 & 1 & & 3 & & 6 & & 9 & & & 26 \\
\hline & MR107 & 7 & & & & & & & & & 1 & & & 8 \\
\hline
\end{tabular}

The number of times each pool was sampled each winter, shown for each time the pool filled during the season $(1,2$, or 3 times). The total number of times the pool was sampled in the entire study is also shown in the last column. Sampling year 01-02 is not shown because no pools were sampled as none filled from July of one year to June of the next based on NOAA records at the Lindbergh Field, San Diego, weather station. ${ }^{1}$

Crustaceans were sampled by sweeping an aquarium net (mesh size $1 \times 0.5 \mathrm{~mm}$ ) through the pool. Net size used ranged from 5 to $15 \mathrm{~cm}^{2}$; size used depended on pool depth. Most pools were sampled by combining three one-meter net sweeps. Pools smaller than $1 \mathrm{~m}$ across were sampled by making

\footnotetext{
$\overline{1 \text { http://cdo.ncd }}$.noaa.gov/ancsum/ACS? stnid=10001444.
}

three top-to-bottom scoops. Samples were rinsed out of nets with soda water to anaesthetize animals and then transferred into $100 \%$ ethyl alcohol. In the laboratory, organisms were transferred to $70 \%$ ethyl alcohol. Every individual from each sample was separated from other material under a dissecting microscope and sorted to lowest possible taxonomic level according to Balcer et al. (1984), Cohen (1982), Fugate (1993), Pennak (1989), and Thorpe \& Covich (1991). Several distinguishable morphotypes of cladocerans and ostracods were only 
identifiable to genus. Several of the ostracod species are apparently undescribed. Identification of taxa was confirmed by taxonomic experts (see Acknowledgements).

Data analysis

For statistical analyses, we dealt with the problem of having multiple non-independent measurements on the same ponds by only using the maximum recorded values of area and depth, and we ln-transformed them to produce more normal distributional properties before analysis. Pond area was calculated using estimated length and width as the major and minor axes of an ellipse. Pond permanence was measured as the total number of 10-14 days sampling periods the pool was filled during each winter season. The sum over the whole study was also calculated, and permanence was In-transformed before analysis to better fit the normal distribution. Species richness for each year was the total number of species found in all samples of that year. Cumulative species richness over the whole study was counted by examining species lists from all years. The maximum withinyear count was not an accurate measure of multi-year species richness because sometimes the number of species was the same from one sampling time to another but some of the species differed. To examine inter-annual variation in species richness, we limited the data set to only the 10 pools that filled in all five sampling years. We tested the hypothesis that the relative rank of each of the 10 pools was the same across all five years by calculating Kendall's concordance coefficient, which extends Spearman's rank correlation to more than two correlated variables (Zar, 1999).

Relationships between pond size variables and species richness were initially explored with scatter plots for each year separately and for the whole study period combined. We calculated correlation coefficients between species richness and the three measures of pond size, using the data summarized across the whole study, to test assumptions of linear regressionbased tests. Variables with strong correlations to each other as well as to species richness were included in path analyses to determine the strength of association of each variable separately on species richness. We used a simple model assuming that the three variables were all intercorrelated and each had a direct effect on

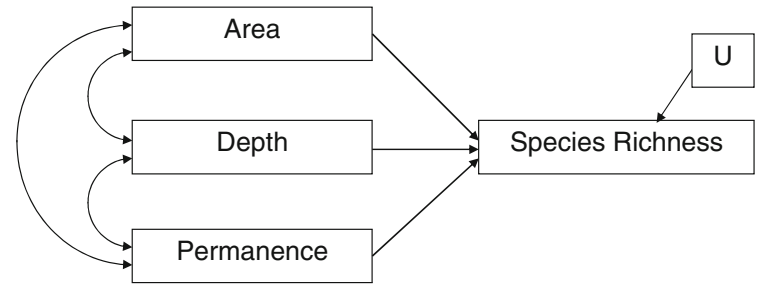

Fig. 1 Schematic of model used in path analysis. Singleheaded arrows represent hypothesized direct effects on species richness and double-headed arrows represent correlations between potential explanatory variables. The variable U represents unexplained variance

species richness (Fig. 1), and we analyzed the data for each winter season separately as well as for the whole study, to see if the same conclusions would be drawn from only one year of study. The path analyses were done in Amos 7.0.0 (Amos Development Corporation, Spring House, PA, 2006).

Patterns in crustacean communities as a whole were explored using clustering. We used the summary occurrence data from all years for each pool and clustered them using furthest neighbor agglomeration and Jaccard's similarity index as the distance measure (McGarigal et al., 2000). Clustering of pools was aligned to complex, pond maximum depth, and total species richness to see if any of these factors were related to species associations. Pond depth was used instead of permanence because over the time scale of the data used for clustering, it was the only significant predictor of species richness. Clustering was done in SPSS v. 11.0 (SPSS Inc., Chicago, IL, 2002).

There were several statistical issues with our data. There were missing data for a number of crustacean samples due to logistical and time constraints. We averaged over multiple pool visits so we were able to estimate all of the variables; however, as a consequence sample sizes differ between variables. Ponds with multiple missing explanatory variables or that were sampled in only one or two years were eliminated from analysis, bringing the total down to 34. One additional pool with incomplete data had to be eliminated from the path analysis. Another issue is that pools were measured repeatedly both within years and over multiple years so samples are not independent; however, by using only maximum values, we are avoiding pseudoreplication. Neither repeated measures nor multivariate approaches could be used on the data set as a whole, because different 
numbers of samples were taken from the pools. We did use the ten pools that filled in all five years to test for inter-annual variation using non-parametric tests.

To test for nestedness with respect to pond permanence, we first arranged presence (1) and absence (0) in matrices with sites in rows and species in columns. We sorted the rows in descending order of permanence and sorted the columns in descending order by column sum. The perfectly nested matrix would have rows with no incidences of a one to the right of a zero. Nestedness analysis requires definition of a metric to compare the observed pattern to perfect nestedness and specification of a null model or way to define what a "random" species assemblage would look like (Wright et al., 1998). We used the discrepancy metric $(D)$ of Brauldi \& Sanderson (1999), which we calculated as the number of absences in the observed data that are occurrences in the perfectly nested matrix with the same row sums. The null model we used is one where species occurrence in randomly generated matrices is based on their actual frequency of occurrence, without holding row sums constant (Jonsson, 2001). We evaluated significance of nestedness by calculating the proportion of 1,000 randomized matrices with a discrepancy as small as or smaller than the observed discrepancy. Rejecting the null hypothesis suggests that the observed pattern is nested. We wrote a program in Matlab 7.0 (The Mathworks, Inc.) to do the nestedness analysis, which is available upon request from the corresponding author.

Phenologies for each species were constructed by first tallying the number of times the species was observed in each sampling period after pond filling. We assumed that each pond filling was independent from all others. If enough occurrences were observed over the study, these tallies clearly showed when species first appeared in the pond and if they disappeared by a particular time. Once we had constructed phenologies for the most commonly observed species, we noticed that they clearly fell into several patterns; so we summarized these as "Types" and present only the types in the section 'Results'.

\section{Results}

We collected a total of 490 samples from 37 pools over the entire study. We found 26 species from four crustacean orders: one anostracan, 9 ostracods, 6 cladocerans, and 3 copepods.

\section{Differences between ponds}

Species richness in any pool within a single season ranged from 1 to 16 and the maximum number of species that were identified from any one pool was 18 (Table 2). Pond filling and species richness both depended heavily on rainfall amount and pattern. During the study, cumulative rainfall for the winter seasons averaged $22.2 \mathrm{~cm}( \pm 13.0 \mathrm{SD})$ and ranged from $7.6 \mathrm{~cm}$ in $01-02$ to $45.2 \mathrm{~cm}$ in 97-98. This high rainfall season was due to an El Niño Southern Oscillation (ENSO) event, which in Southern California brings unusually heavy rains. Two pools stayed filled continuously for nine sampling periods (about 4 months) in the ENSO season, but a more typical pattern was for pools to fill and dry once or twice during the winter (Table 1).

There was a clear pattern of higher species richness in years with higher rainfall. We examined this pattern in more detail using only the 10 pools that were sampled in all five years. Although we cannot disentangle the effect of "year" from that of "rainfall," the pattern of increasing species richness with increasing rainfall is worth exploring further (Fig. 2A). Pools also differed from one another consistently in species richness (Fig. 2B), which causes the large variance around year means in Fig. 2A. Pools that had the most species in wet years also tended to have the most species in dry years. We tested the hypothesis that pool rank from year to year is uncorrelated, and rejected it $\left(\chi^{2}=34.6\right.$, $\mathrm{df}=9$, $P<0.0001$ ), supporting our observation that pools consistently have higher or lower species richness relative to one another, even if the total number of species detected in the year is only a portion of the complete fauna. Another way of saying this is that although absolute species richness varies from year to year for any pool, the relative species richness among a group of pools is about the same from year to year.

Species-pond size relationship

Species richness showed moderately strong correlation coefficients with pond area (0.60), depth (0.74), and permanence $(0.72)$, and these variables were all correlated with one another with $r>0.5$. Independent 


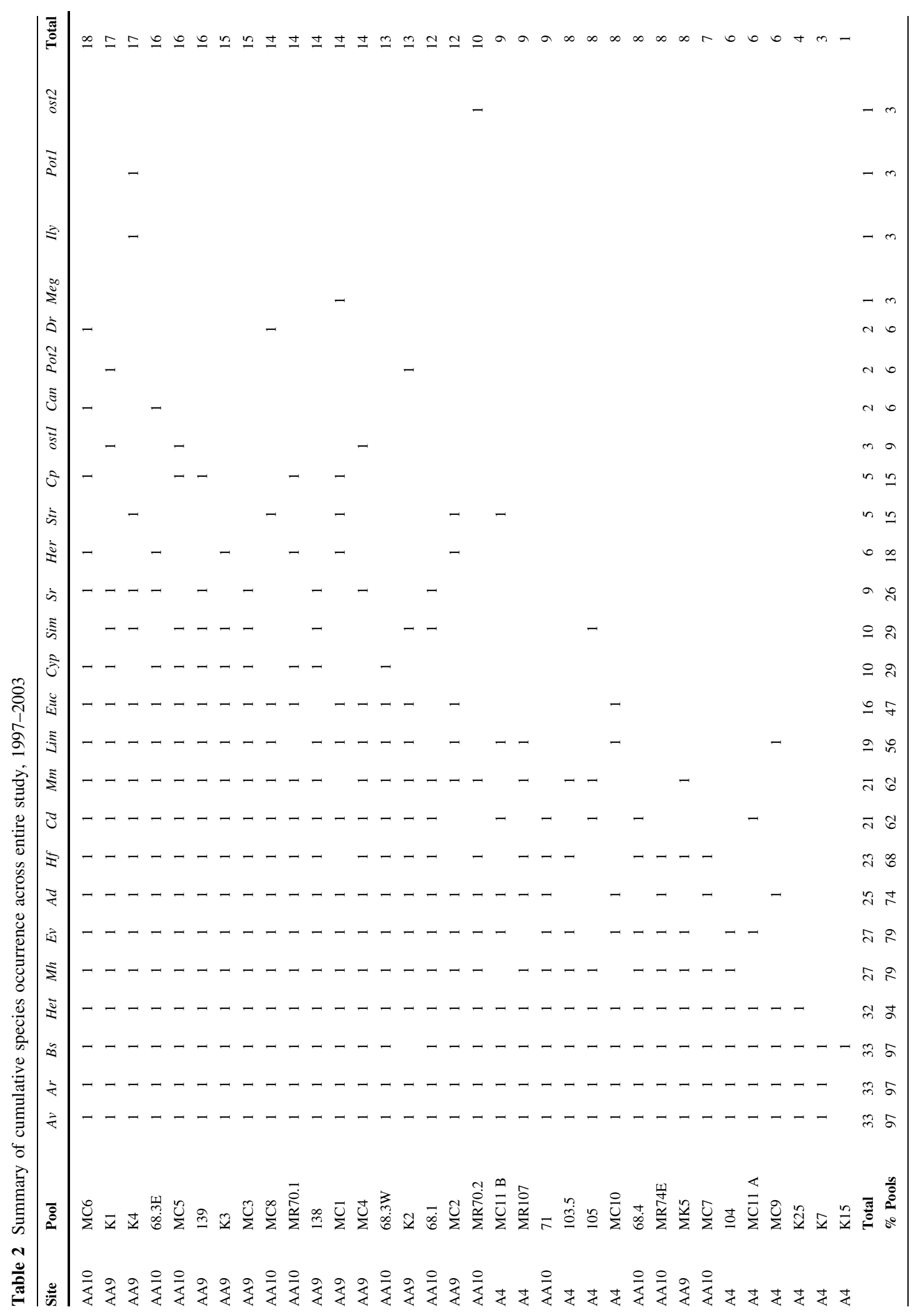



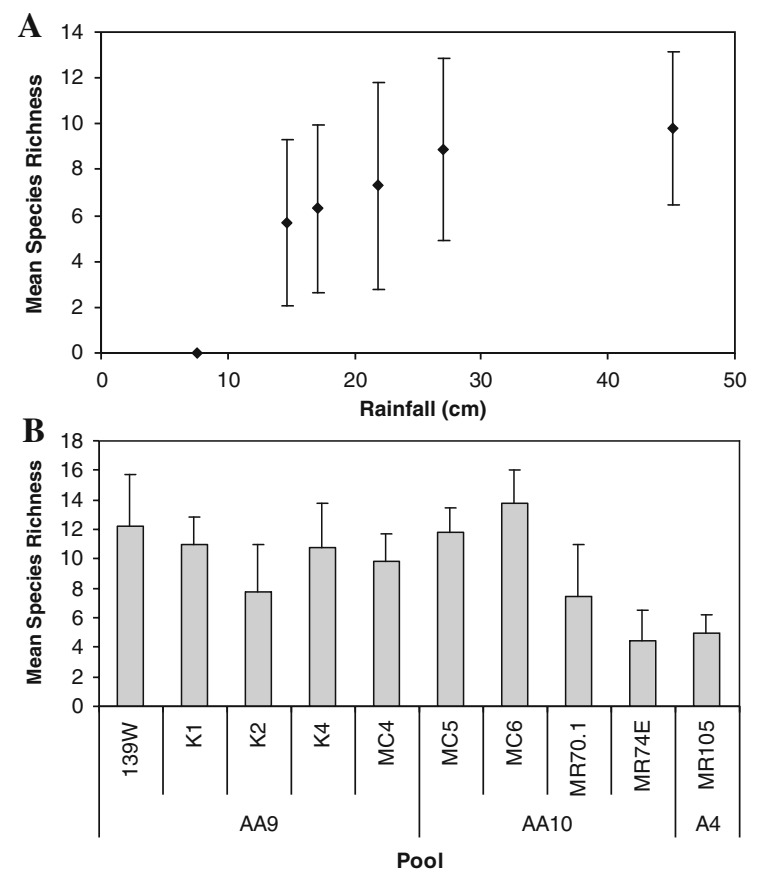

Fig. 2 Inter-annual and inter-pool variation, for the subset of 10 pools that were sampled in all seasons. Graph A shows mean species richness plotted against total rainfall, with error bars showing variation across pools within years. Graph B shows mean species richness for each pool, with error bars showing variation across years. The complex to which each pool belongs is also shown by division along the $\mathrm{x}$-axis. Error bars are one standard deviation

contributions to species richness of the three correlated pond size variables were calculated using path analysis. Results of the path analysis showed that for the overall data and for the last three sampling seasons, the path coefficient for depth was the highest and the only one that was significant (Table 3). In the year of the ENSO event, the pattern was reversed, with depth having the lowest path coefficient, and area and permanence both being highly significant. None of the variables were significant for the 98-99 data, but they had such small a sample size ( 9 pools) that results should be interpreted with caution anyway.

\section{Patterns in Crustacean assemblages}

Species occurred in either $>50 \%$ of pools or in $<30 \%$ of pools consistently from year to year (single year species lists not shown), so species can be designated as widespread or rare, respectively. The rare species 
Table 3 Results of path analysis

\begin{tabular}{|c|c|c|c|}
\hline Time & Factor & $\beta$ & $P$-value \\
\hline \multicolumn{4}{|l|}{ Overall } \\
\hline \multirow[t]{3}{*}{$n=34$} & Area & 0.24 & 0.089 \\
\hline & Depth & 0.43 & 0.020 \\
\hline & Permanence & 0.22 & 0.193 \\
\hline \multicolumn{4}{|l|}{ 97-98 } \\
\hline \multirow[t]{3}{*}{$n=33$} & Area & 0.41 & 0.007 \\
\hline & Depth & -0.16 & 0.274 \\
\hline & Permanence & 0.44 & 0.009 \\
\hline \multicolumn{4}{|l|}{ 98-99 } \\
\hline \multirow[t]{3}{*}{$n=9$} & Area & 0.42 & 0.163 \\
\hline & Depth & 0.06 & 0.860 \\
\hline & Permanence & 0.34 & 0.368 \\
\hline \multicolumn{4}{|l|}{ 99-00 } \\
\hline \multirow[t]{3}{*}{$n=19$} & Area & -0.01 & 0.946 \\
\hline & Depth & 0.55 & 0.018 \\
\hline & Permanence & 0.24 & 0.266 \\
\hline \multicolumn{4}{|l|}{ 00-01 } \\
\hline \multirow[t]{3}{*}{$n=33$} & Area & 0.21 & 0.160 \\
\hline & Depth & 0.40 & 0.032 \\
\hline & Permanence & 0.23 & 0.159 \\
\hline \multicolumn{4}{|l|}{$02-03$} \\
\hline \multirow[t]{3}{*}{$n=34$} & Area & 0.22 & 0.093 \\
\hline & Depth & 0.71 & $<0.001$ \\
\hline & Permanence & -0.02 & 0.887 \\
\hline
\end{tabular}

Time is the period over which the analysis was done, with number of pools $(n)$ included in the sample below. Factors are the hypothesized explanatory variables (see Fig. 1). All three factors were $\ln$-transformed before analysis. Area and depth were the maximum values measured for the time period, and permanence was the sum of the sampling periods the pool was filled during the time period. The variable $\beta$ is the path coefficient, or standardized regression coefficient calculated in the path analysis. The $P$-value of $\beta$ is shown, with values $<0.05$ in bold. One Type I error is expected table-wide at this $\alpha$-level

were always found in pools with $>8$ species and were not detected in all years. Similarity of crustacean communities between pools and between complexes was investigated using cluster analysis. The resulting diagram shows five main clusters (Fig. 3). The deepest split (E) is between the pool K15, which only has $B$. sandiegonensis, and all others, which have three or more species. Groups A, B, and C are distinguished from Group $\mathrm{D}$ in that pools in $\mathrm{D}$ are missing the cladoceran Moina micrura. Group A pools are missing one of Eucypris virens, Alona c.f. diaphana, or Ceriodaphnia dubia, which are all present in the B and C pools. Finally, Group B and C pools are distinguished in that $\mathrm{C}$ pools have Herpetocypris and B pools do not.

The clusters are somewhat related to the putative explanatory variables. Species richness shows a fairly strong pattern, with group B and C pools with 12 or more species and the other groups with 10 or fewer. Pool depths show no clear pattern among the groupings. Spatial patterns are much clearer. There is a strong distinction between A4 and the other two complexes, especially AA9. A4 pools only occur in clusters A, D, and E, and the AA10 pools within cluster D are together in a subcluster. Based on their geographic locations and historic connectivity, we would expect AA9 and AA10 to be more similar to one another than to A4.

\section{Nestedness}

The matrix of accumulated species occurrence over all years for all pools showed that longer-lived ponds contained more species (Table 2). This matrix was highly significantly nested when sorted by pond permanence (Table 4). When that matrix was broken down into separate matrices for each year of sampling, each of these was also significantly nested (Table 4). When the total matrix was broken down into separate matrices for each complex, only AA10 was significantly nested at the 0.05 level (Table 4). This means that over larger spatial scales, the pattern of species occurrence in the habitat type is nested, but that over smaller spatial scales, i.e., within complexes, pools with high species richness do not necessarily have all species present in the complex.

\section{Phenologies}

We identified five patterns that summarize phenologies of commonly sampled crustaceans (Fig. 4). Type (I) are species that appear within a week of pond filling, and continue to be present until the ponds dry. These include species of copepods, cladocera, and ostracods, which may have multiple generations in a pond and then switch to producing resting cysts later due to environmental cues. Type II species take longer to emerge or mature, and yet may truncate their life cycles before the pond dries if it lasts unusually long. Species in Types III and IV take even longer to emerge or mature, and have a life span 
Fig. 3 Clustering diagram showing similarity of pools based on crustacean community. Branch tips are pools, identified by name/ number, and complex.

Variables potentially associated with clustering are also included:

cumulative species richness (R) and maximum depth (D), in $\mathrm{cm}$, during entire study. Distances separating pools at branch points are in an arbitrary scale across the top of the diagram. Major branching points are lettered A-E for discussion in the text

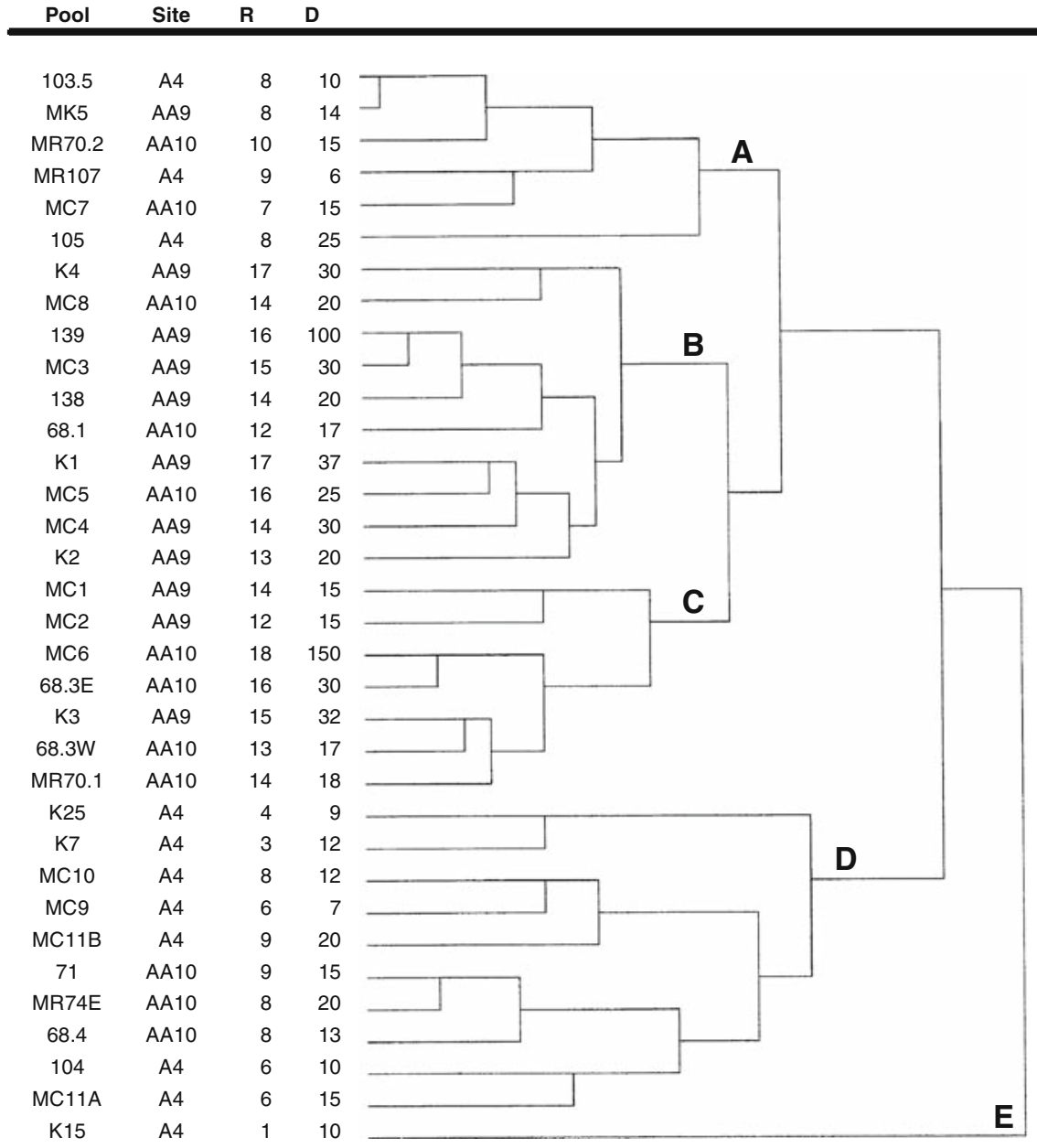

limited to about the average ponding duration in the study, 8 weeks. Type V species appear at the same time as Type IV species, disappear from the pond, and appear again later in the ponding duration. Type I and Type $\mathrm{V}$ species are the only ones that seem to take advantage of reduced competition in the longer duration ponds, after species Types III and IV have disappeared, but they are not exclusively dependent upon this later time period. The two species identified as Type $\mathrm{V}$ occur in more than $50 \%$ of the pools, so they are not driving the nestedness pattern. Unfortunately, we were unable to determine phenologies for any of the rare species that are responsible for the nested pattern; they occurred so infrequently that no clear patterns emerged. Therefore, we were unable to test the hypothesis that the species occurring only in the longer-lived ponds were limited to these ponds by long developmental times. 
Sampling Period After Pond Filling (in 10-14 d sampling periods)

\begin{tabular}{l|lllllllll} 
& 1 & 2 & 3 & 4 & 5 & 6 & 7 & 8 & 9 \\
\hline Type I & & & & & & & & \\
\hline Type II & & & & & & & & & \\
\hline Type III & & & & & & & & & \\
\hline Type IV & & & & & & & & & \\
\hline Type V & & & & & & & & & \\
\hline
\end{tabular}

Fig. 4 Phenologies of species occurrence. Black bars indicate the periods of time when the species in each type can be observed in pools. Species clearly in each category are as follows: (I) M. hirsuticornis, E. virens, H. franciscanus, A. robustus,

\section{Discussion}

We found strong evidence that ponds differ from one another in the number of species that they support, and that this pattern is consistent from year to year. This pattern was clearly due to pond permanence when cumulative species richness was considered in the nestedness analysis (Table 4), with longer duration ponds having more species than shorter duration ponds. However, pond depth was a better predictor of absolute species richness overall than pond permanence (Table 3). Since pond depth and pond duration are strongly correlated, however, these results are not contradictory.

Although we were unable to critically test the species-sorting hypothesis with our data, our results are consistent with the growing literature implicating species sorting as a dominant mechanism structuring freshwater pond communities. Further work in this system to test the assumption that dispersal is not limiting would add value to our results. Interestingly, the fine scale of our sampling allowed us to show that although the overall community is consistent with a species-sorting paradigm, there were exceptions to the pattern. The few species that were found in all or most ponds are the ones with the shortest time to maturity. If they are capable of persistence in any pond, then the patch dynamics paradigm (where all patches offer the same resources) may explain their distribution patterns rather than species-sorting dynamics.

The evidence that some pools have consistently higher species richness than others includes the observation that pools tend to differ more from one another within a year than they do within themselves between years (Fig. 2B). Although the number of species detected tends to increase with rainfall (Fig. 2A), in dry years each pool tends to have a subset of the species observed within it in wetter
A. vernalis; (II) C. dubia; (III) E. sp. 2, H. incongruens; (IV) B. sandiegonensis, M. micrura; and (V) A. diaphana, Limnothycyre sp.

years, rather than a different set of species. This means that any survey of temporary pond faunas can compare absolute species richness fairly reliably between pools sampled in the same year. If ponds are sampled in years with different environmental conditions, however, relative species richness among pools should be used for comparison.

We found that different measures of pond size differed in their ability to predict species richness, and that their ability varied from year to year. Maximum pond depth was the only pond-size measure with a significant path coefficient using data integrated across the whole study (Table 3). When sampling years were looked at individually, three of the years had the same results as the overall data, but in the El Niño year, pond area and permanence had significant path coefficients while depth did not. This result clearly shows that a single year's data may not reflect longer-term patterns in species richness. Other studies showing high explanatory power of different variables than we did (e.g. Brooks \& Hayashi, 2002; March \& Bass, 1995) are on pools in quite different ecological settings than the San Diego pools or are over much larger spatial scales and include several geomorphic pond types (King et al., 1996; Fryer, 1985). We agree with Brooks \& Hayashi (2002) that the size and shape of the pond basin, in concert with processes regulating filling and drying, determine how strongly depth, area, volume, and ponding duration are correlated and which is the best predictor of habitat quality. Therefore the relative importance of these variables as predictors of species richness will depend on pond type. This could explain the lack of consensus in the temporary pond literature on the ability of island biogeography theory's relevance to temporary ponds.

Our finding of significant nestedness based on habitat permanence supports the hypothesis that 
species sorting determines crustacean metacommunity structure. This pattern was also observed by Baber et al. (2004), who showed that pond faunas were nested based on hydroperiod and area (which were correlated). McAbendroth et al. (2005) also found that the ephemeral pond taxa showing the strongest nestedness were those with narrower habitat tolerance and poorer dispersal ability (i.e., crustaceans, rather than insects). In contract, Urban (2004) did not detect nestedness in pond faunas. However, it is not surprising that his results differ from ours, because he sampled across both a broader range of taxa than we did, including amphibians, crustaceans, insects, and other invertebrates, and a wider range of pond hydroperiods, including permanent ponds. There are several reasons that nestedness may be detected. Habitats may fall along a gradient of increasing heterogeneity and total niches available, or there may be a gradient of ecological conditions, to which different species show different specialization or tolerance (Hylander et al., 2005). The analysis method is unable to tell us which pattern we are detecting. We were unable to confirm that the species causing the nested pattern were dependent on longlived pools due to life history adaptations and consider this an interesting problem for further work. It could be the case that longer-lived ponds have different resources available-algal growth, for example-to which species are responding.

We found differences in metacommunity patterns over different spatial scales in two of our analyses. Crustacean faunas were nested at the regional scale, but not necessarily at the complex scale. Differences in nestedness across different spatial scales have also been shown for rotifer metacommunities (Fontaneto et al., 2005). Fontaneto et al. (2005) suggested that this pattern was related to differing dispersal ability across these scales. If so, our results suggest that crustaceans are better able to disperse over withincomplex distances than over between-complex distances. Evidence for biological significance of intercomplex distances is notable in the cluster analysis of the whole crustacean fauna. One of the three complexes (A4) was separated from the other two in the clustering pattern (Fig. 3). This complex is also more geographically distant from complexes AA9 and AA10, although potential barriers to dispersal such as freeways, airports, and housing developments separate all the complexes. Our empirical results confirm theoretical predictions that scale is important to detecting metacommunity patterns (Jenkins, 2006; Mouquet \& Loreau, 2002).

The temporal and spatial scales of our work fall at the intersection of local and regional processes. We observed that some of the patterns in metacommunity structure differed at the within-complex and betweencomplex scales. At the regional scale, dispersal limitation has been hypothesized to dictate species distributions, whereas at the local level, interspecific interactions can exert strong influences on species and prevent their establishment even if they are able to disperse there (Bohonak \& Jenkins, 2003). Although some passively dispersing pond organisms such as crustaceans may be capable of extensive dispersal (Louette \& DeMeester, 2005), other studies have shown evidence of dispersal limitation, for example in copepods (Stemberger, 1995). In permanent ponds, established communities have been shown to be resistant to invasion by immigrant species (Lukaszewki et al., 1999; Shurin, 2000). Since temporary ponds dry and interspecific interactions are reset at each pond filling, different processes may determine the success of immigration than in permanent ponds (Schneider \& Frost, 1996). Although our results do not specifically address dispersal ability, we can draw a few conclusions. We found a few species in every pool, suggesting that at least for some species dispersal is possible across the region. Dispersal may be infrequent for many pond invertebrates in the short term (Holland \& Jenkins, 1998; Jenkins \& Underwood, 1998) but over the 4,00010,000 years that current geologic and ecological conditions have prevailed (Axelrod, 1978), it is plausible that every species has had opportunities to colonize the region.

Indeed, short-term dispersal will be extremely difficult to measure in this environment. Although species turnover could be due to extinction and rescue from other pools, it is much more likely that appearance in ponds is generally from the established egg bank and not a result of frequent colonization and extinction events (Donald, 1983). We think that the appearance and disappearance of species that we observed over a series of years was extremely unlikely to have been due to extinction and recolonization because of the high numbers of individuals present in ponds in the years that they did appear. It would be interesting to measure the relative 
importance of "dispersal from the past" versus immigration from other ponds (Bohonak \& Jenkins, 2003). This might be possible for a few species in this system using genetic markers. Although Leibold et al. (2004) recognized that dormancy could have important effects moderating other metacommunity processes, we do not think that the extent to which storage of species in the cyst bank can alter shortterm community dynamics has been generally recognized, and is especially important in ephemeral ponds.

Acknowledgments We are grateful to C. Cobb of MCASM for making this work possible. We thank J. Holtz, D. Parsick, and C. Esparza for major contributions to field and laboratory work. We also acknowledge the contribution to the project of an army of undergraduate students, too numerous to mention by name. B. Hann, J. Reid, C. Ham, M. Angelos, and M. Forester confirmed identifications of species. We also thank A. Bohonak and T. McGlynn for helpful discussion of statistical and ecological issues. Two anonymous reviewers also provided comments that helped us greatly improve the manuscript. This work was funded by the Department of Defense (Letter of Agreement N68711-99-LT-90028) and the University of San Diego. This research was conducted under U.S. Fish and Wildlife Service permit TE-787037-1.

\section{References}

Axelrod, D. I., 1978. The origin of coastal sage vegetation, Alta and Baja California. American Journal Botany 65: 1117-1131.

Baber, M. J., E. Fleishman, K. J. Babbitt \& T. L. Tarr, 2004. The relationship between wetland hydroperiod and nestedness patterns in assemblages of larval amphibians and predatory macroinvertebrates. Oikos 107: 16-27.

Balcer, M. D., N. L. Korda \& S. I. Dodson, 1984. Zooplankton of the Great Lakes: A Guide to Identification and Ecology of the Common Crustacean Species. University of Wisconsin Press, Madison, Wisconsin.

Bauder, E. T., 1987. Species assortment along a small-scale gradient in San Diego vernal pools. Ph.D. dissertation, University of California, Davis: 275 p.

Bauder, E. T. \& S. McMillan, 1998. Current distribution and historical extent of vernal pools in Southern California and Baja Mexico. In Witham, C. W., E. Bauder, D. Belk, W. Ferren \& R. Ornduff (eds), Ecology, Conservation, and Management of Vernal Pool Ecosystems. California Native Plant Society. Sacramento, CA: 56-60.

Bohonak, A. J. \& D. G. Jenkins, 2003. Ecological and evolutionary significance of dispersal by freshwater invertebrates. Ecology Letters 6: 783-796.

Brauldi, R. A. \& J. G. Sanderson, 1999. Nested species subsets, gaps, and discrepancy. Oecologia 119: 256-264.

Brendonck, L., 1996. Diapause, quiescence, hatching requirements: what we can learn from large freshwater branchiopods
(Crustacea: Branchipoda: Anostraca, Notostraca, Conchostraca). Hydrobiologia 320: 85-97.

Brooks, R. T., 2000. Annual and seasonal variation and the effects of hydroperiod on benthic macroinvertebrates of seasonal forest ("vernal") ponds in central Massachusetts, USA. Wetlands 20: 707-715.

Brooks, R. T. \& M. Hayashi, 2002. Depth-area-volume and hydroperiod relationships of ephemeral (vernal) forest pools in southern New England. Wetlands 22: 247-255.

Cohen, A. C., 1982. Ostracoda. In Parker, S. (ed.), Synopsis and Classification of Living Organisms, Vol. 2. McGrawHill Book Co., New York: 181-202.

Cottenie, K. E., N. Michels, L. Nuytten \& De Meester, 2003. Zooplankton metacommunity structure: regional vs local processes in highly interconnected ponds. Ecology 84: 991-1000.

Donald, D. B., 1983. Erratic occurrence of anostracans in a temporary pond: colonization and extinction or adaptation to variations in annual weather? Canadian Journal Zoology 61: 1492-1498.

Dodson, S. L., 1992. Predicting crustacean zooplankton species richness. Limnology and Oceanography 37: 848-856.

Ebert, T. A. \& M. L. Balko, 1987. Vernal pools as islands in space and time. In Jain, S. \& P. Moyle (eds), Vernal Pools and Intermittent Streams. Institute of Ecology Publication, University of California, Davis: 90-101.

Eitam, A., L. Blaustein, K. Van Damme, H. J. Dumont \& K. Martens, 2004. Crustacean species richness in temporary pools: relationships with habitat traits. Hydrobiologia 525: 125-130.

Figuerola, J. \& A. J. Green, 2002. Dispersal of aquatic organisms by waterbirds: a review of past research and priorities for future. Freshwater Biology 47: 483-494.

Fontaneto, D., G. Melone \& C. Ricci, 2005. Connectivity and nestedness of the meta-community structure of moss dwelling bdelloid rotifers along a stream. Hydrobiologia 542: 131-136.

Fryer, G., 1985. Crustacean diversity in relation to the size of water bodies: some facts and problems. Freshwater Biology 15 : 347-361.

Fugate, M. L., 1993. Branchinecta sandiegonensis, a new species of fairy shrimp (Crustacea: Anostraca) from Western North America. Proceedings Biological Society Washington 106: 296-304.

García, C. M., R. García-Ruiz, M. Rendón, F. X. Niell \& J. Lucena, 1997. Hydrological cycle and interannual variability of the aquatic community in a temporary saline lake (Fuente de Piedra, Southern Spain). Hydrobiologia 345: 131-141.

Graham, T. B., 2002. Survey of aquatic microinvertebrates and amphibians at Wapatki National Monument, Arizona, USA: an evaluation of selected factors affecting species richness in ephemeral ponds. Hydrobiologia 486: 215-224.

Hall, D. L., M. E. Willig, D. L. Moorhead, R. W. Sites, E. B. Fish \& T. R. Mollhagen, 2004. Aquatic macroinvertebrate diversity of playa wetlands: the role of landscape and island biogeographic characteristics. Wetlands 24: 77-91.

Hathaway, S. A. \& M. A. Simovich, 1996. Factors affecting the distribution and co-occurrence of two southern Californian anostracans (Branchiopoda), Branchinecta sandiegonensis 
and Streptocephalus woottoni. Journal Crustacean Biology 16: 669-677.

Havel, J. E. \& J. B. Shurin, 2004. Mechanisms, effects, and scales of dispersal in freshwater zooplankton. Limnology Oceanography 49: 1229-1238.

Helm, B. P., 1998. Biogeography of eight large branchiopods endemic to California. In Witham, C. W., E. Bauder, D. Belk, W. Ferren \& R. Ornduff (eds), Ecology, Conservation, and Management of Vernal Pool Ecosystems. California Native Plant Society, Sacramento, CA: 124-139.

Holland, R. F. \& S. K. Jain, 1981. Insular biogeography of vernal pools in the Central Valley of California. American Naturalist 117: 24-37.

Holland, T. A. \& D. G. Jenkins, 1998. Comparison of processes regulating zooplankton assemblages in new freshwater ponds. Hydrobiologia 387/388: 207-214.

Hylander, K., C. Nilsson, B. G. Jonsson \& T. Gothner, 2005. Differences in habitat quality explain nestedness in a land snail meta-community. Oikos 108: 351-361.

Jeffries, M. J., 2001. Modeling the incidence of temporary pond microcrustacea: the importance of dry phase and linkage between ponds. Israel Journal Zoology 47: 445-458.

Jenkins, D. G. 2006. In search of quorum effects in metacommunity structure: species co-occurrence analyses. Ecology 87: 1523-1531.

Jenkins, D. G. \& M. O. Underwood, 1998. Zooplankton may not disperse readily in wind, rain, or waterfowl. Hydrobiologia 387/388: 15-21.

Jonsson, B. G., 2001. A null model for randomization tests of nestedness in species assemblages. Oecologia 127: 309-313.

Jocqué, M., B. J. Riddoch \& L. Brendonck, 2007. Successional phases and species replacements in freshwater rock pools: towards a biological definition of ephemeral systems. Freshwater Biology 52: 1734-1744.

King, J. L., M. A. Simovich \& R. C. Brusca, 1996. Species richness, endemism and ecology of crustacean assemblages in northern California vernal pools. Hydrobiologia 328: 85-116.

Kneitel, J. M. \& T. E. Miller, 2003. Dispersal rates affect species composition in metacommunities of Sarracenia purpurea inquilines. American Naturalist 162: 165-171.

Leibold, M. A. \& J. Norberg, 2004. Biodiversity in metacommunities: plankton as complex adaptive systems? Limnology Oceanography 49: 1278-1289.

Leibold, M. A., M. Holyoak, N. Mouquet, P. Amarasekare, J. M. Chase, M. F. Hoopes, R. D. Holt, J. B. Shurin, R. Law, D. Tilman, M. Loreau \& A. Gonzalez, 2004. The metacommunity concept: a framework for multi-scale community ecology. Ecology Letters 7: 601-613.

Louette, G. \& L. DeMeester, 2005. High dispersal capacity of cladoceran zooplankton in newly founded communities. Ecology 86: 353-359.

Lukaszewki, Y., S. E. Arnott \& T. M. Frost, 1999. Regional versus local processes in determining zooplankton community composition of Little Rock Lake, Wisconsin, USA. Journal Plankton Research 21: 991-1003.

Mahoney, D. L., M. A. Mort \& B. E. Taylor, 1990. Species richness of calanoid copepods, cladocerans and other branchiopods in Carolina Bay temporary ponds. American Midland Naturalist 123: 244-258.

March, F. \& D. Bass, 1995. Application of island biogeography theory to temporary pools. Journal Freshwater Biology 10: 83-85.

McAbendroth, L., A. Foggo, S. D. Rundle \& D. T. Bilton, 2005. Unraveling nestedness and spatial pattern in pond assemblages. Journal Animal Ecology 74: 41-49.

McGarigal, K., S. Cushman \& S. Stafford, 2000. Multivariate Statistics for Wildlife and Ecology Research. SpringerVerlag, New York.

McArthur, R. H. \& E. O. Wilson. 1967. The Theory of Island Biogeography. Princeton University Press: 224 pp.

Mouquet, N. \& M. Loreau, 2002. Coexistence in metacommunities: the regional similarity hypothesis. American Naturalist 159: 420-426.

Mouquet, N. \& M. Loreau, 2003. Community patterns in source-sink metacommunities. American Naturalist 162: 544-557.

Pennak, R. W., 1989. Fresh-water invertebrates of the United States. Protozoa to Mollusca, 3rd edn. John Wiley (Interscience), New York.

Philippi, T. E., M. A. Simovich, E. T. Bauder \& J. A. Moorad, 2001. Habitat ephemerality and hatching fraction of a diapausing anostracan (Crustacea: Branchiopoda). Israel Journal of Zoology 47: 387-395.

Ripley, B. J., J. Holtz \& M. A. Simovich, 2004. Cyst bank lifehistory model for a fairy shrimp from ephemeral ponds. Freshwater Biology 49: 221-231.

Rundle, S. D., A. Foggo, V. Choiseul \& D. T. Bilton, 2002. Are distribution patterns linked to dispersal mechanism? An investigation using pond invertebrate assemblages. Freshwater Biology 47: 1571-1581.

Schneider, D. W. \& T. M. Frost, 1996. Habitat duration and community structure in temporary ponds. Journal of the North American Benthological Society. 15: 64-86.

Shurin, J. B., 2000. Dispersal limitation, invasion resistance, and the structure of pond zooplankton communities. Ecology 81: 3074-3086.

Stemberger, R. S., 1995. Pleistocene refuge areas and postglacial dispersal of copepods of the northeastern United States. Canadian Journal of Fisheries and Aquatic Science 52: 2197-2210.

Stevens, P. H. \& D. G. Jenkins, 2000. Analyzing species distributions among temporary ponds with a permutation test approach to the join-count statistic. Aquatic Ecology 34: 91-99.

Thorpe, J. H. \& A. P. Covich, 1991. Ecology and Classification of North American Freshwater Invertebrates. Academic Press, New York.

Urban, M. C., 2004. Disturbance heterogeneity determines freshwater metacommunity structure. Ecology 85: 29712978.

Vanschoenwinkel, B., S. Gielen, M. Seaman \& L. Brendonck, 2007. Any way the wind blows-frequent wind dispersal drives species sorting in ephemeral aquatic communities. Oikos 117: 125-134.

Wilson, D. S., 1992. Complex interactions in metacommunities, with implications for biodiversity and higher levels of selection. Ecology 73: 1884-2000. 
Wiggins, G. B., R. J. Mackay \& I. M. Smith, 1980. Evolutionary and ecological strategies of animals in annual temporary ponds. Archiv Fur Hydrobiologie Supplement 58: 97-206.

Williams, W. D., 1985. Biotic adaptations in temporary lentic waters, with special reference to those in semi-arid and arid regions. Hydrobiologia 125: 85-110.

Wissinger, S. A., A. J. Bohonak, H. H. Whiteman \& W. S. Brown, 1999. Subalpine Wetlands in Colorado: habitat permanence, Salamander predation and invertebrate communities. In Batzer, D. P., R. B. Russell \& S. A. Wissenger (eds), Invertebrates in Freshwater Wetlands of North America: Ecology and Management. Wiley, Inc: 757-790.

Wright, D. H., B. D. Patterson, G. M. Mikkelson, A. Cutler \& W. Atmar, 1998. A comparative analysis of nested subset patterns on species composition. Oecologia 113: 1-20.

Zar, J. H., 1999. Biostatistical Analysis, 4th edn. Prentice Hall, Upper Saddle River, New Jersey. 